Universidad de Lima

Facultad de Ciencias Empresariales y Económicas

Carrera de Marketing

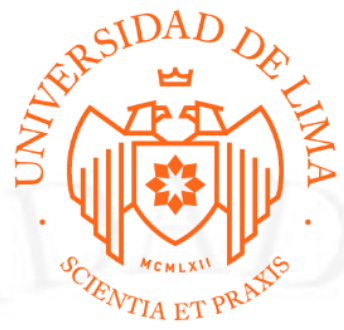

\title{
SUSTENTACIÓN DE CASO: AEROLÍNEA EMIRATES
}

Trabajo de suficiencia profesional para optar el Título Profesional de Licenciado en Marketing

Sustentación de caso

\section{Marcia Ximena Rivera Rivera}

Código 20121102

Lima - Perú

mayo de 2019 


\section{CASE STUDY ANALYSIS: EMIRATES AIRLINES}




\section{TABLA DE CONTENIDO}

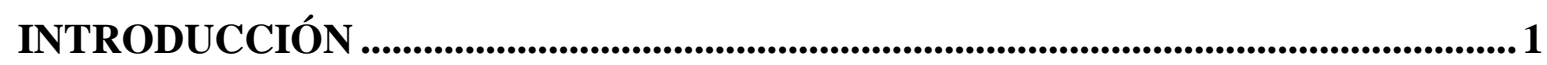

CAPÍTULO I: CONTEXTO DE LA EMPRESA …................................................2

1.1 Descripción, antecedentes de la industria y fortalezas de Aerolíneas Emirates ........ 2

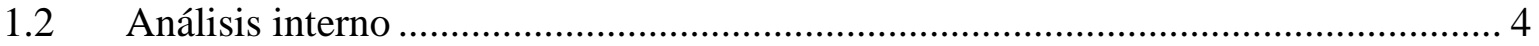

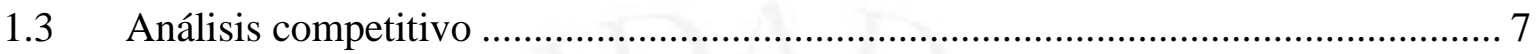

1.4 Análisis Externo .......................................................................................... 9

CAPÍTULO II: DIAGNÓSTICO DEL MARKETING ESTRATÉGICO DE LA

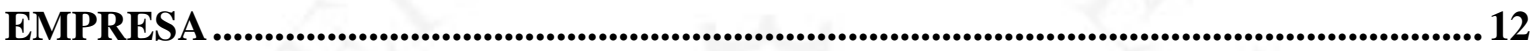

2.1 Análisis de estrategia de marketing orientada hacia los clientes ............................. 12

2.2 Planeamiento estratégico de Marketing ………………...................................... 12

2.3 Descripción y análisis de la estrategia corporativa de la empresa ........................... 13

$2.4 \quad$ Estrategia genérica ........................................................................................... 14

2.5 Estrategia competitiva........................................................................... 15

2.6 Estrategia de crecimiento ………………………......................................... 16

$2.7 \quad$ Descripción del Brand Equity ………………………......................................... 17

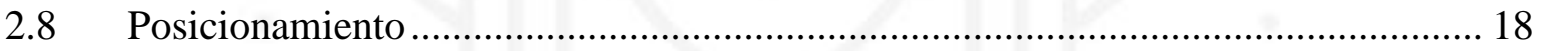

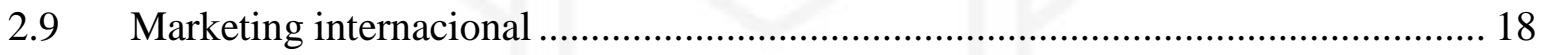

CAPÍTULO III: DESCRIPCIÓN DEL PROBLEMA EN MARKETING OPERATIVO........................................................................................................................ 20

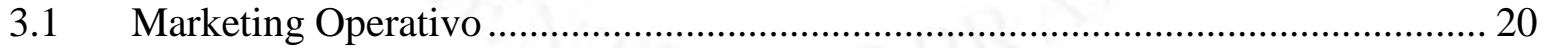

3.2 Descripción de servicio ................................................................................... 20

3.2.1 La flor de los servicios complementarios ................................................................2

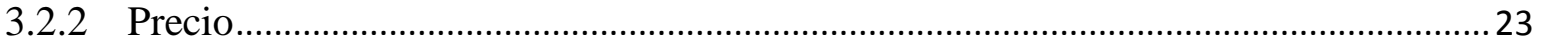

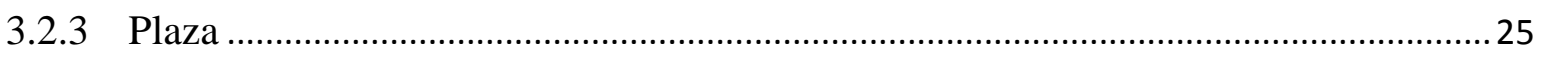

3.2.4 Comunicaciones integradas ...................................................................................2

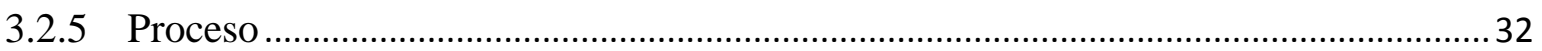

CAPITULO IV: GESTIÓN Y PROCESO DE VENTAS ...................................................33

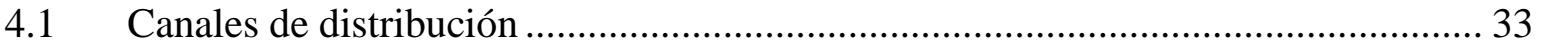


4.2 Gestión de trade marketing ........................................................................ 34

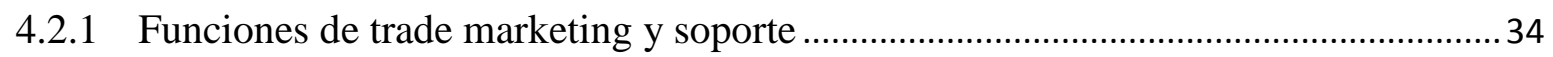

CAPITULO V : ANÁLISIS DE RESULTADOS............................................................ 36

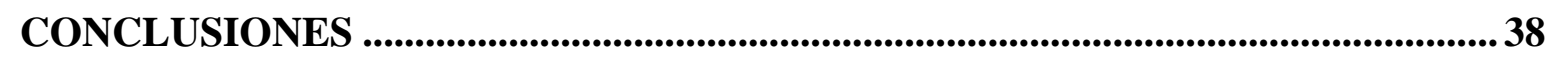

RECOMENDACIONES ........................................................................................ 40

REFERENCIAS .................................................................................................... 41 


\section{INDICE DE TABLAS}

Tabla 1.1 Crecimiento del mercado global en los próximos 5 años ................................ 3

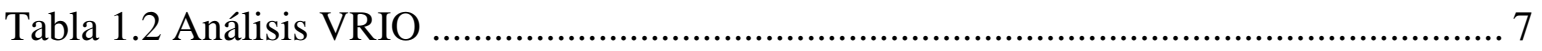

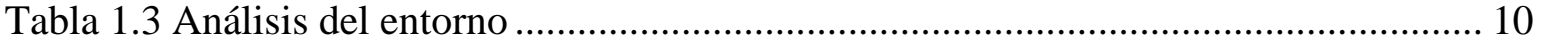

Tabla 1.4 Análisis del entorno (Continuación) .............................................................. 11

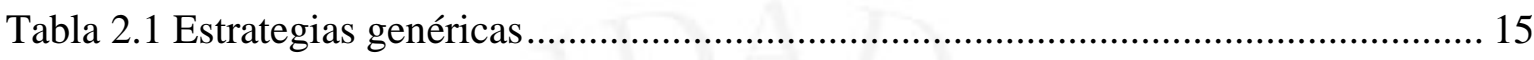

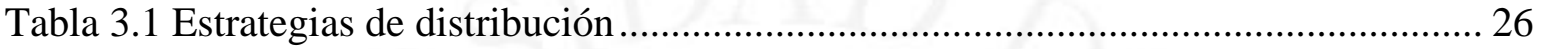




\section{ÍNDICE DE FIGURAS}

Figura 1.1 Tamaño de mercado global …............................................................. 3

Figura 1.2 Resumen competidores regionales claves .............................................. 9

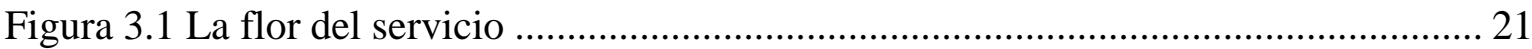

Figura 3.2 Ubicación de sedes al nivel mundial de Aerolíneas Emirates ........................... 27

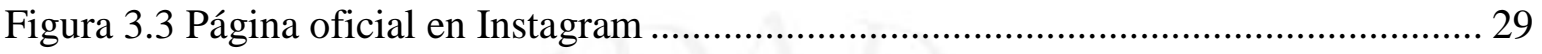

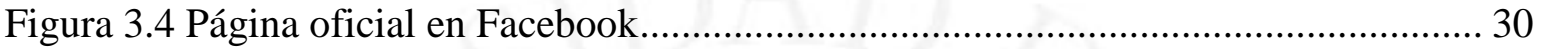

Figura 3.5 Flujograma del servicio ....................................................................... 32

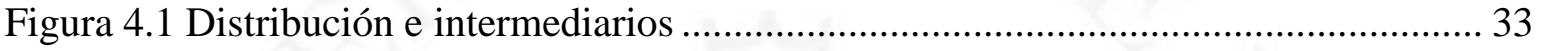




\section{INTRODUCCIÓN}

Aerolíneas Emirates fue fundada en 1985 en Dubái, sin duda fue una historia de éxito global. En tan solo 25 años la aerolínea había crecido hasta convertirse en la tercera aerolínea más grande por capacidad y la más grande por cantidad de pasajeros internacionales.

Emirates fue precursor de los mercados emergentes, no muchas aerolíneas buscaban expandirse de dicha manera, pero la marca busco establecerse con un modelo de negocio único, donde la competencia no tenía acceso. Asimismo, Emirates buscaba generar un impacto único en los clientes que confiaban en la marca, generando una experiencia única con valor agregado durante los trayectos que brindaba de ciudad a ciudad.

Poco a poco la aerolínea empezó a tener una aceptación muy grande en el mercado, al igual que, es reconocida al nivel mundial por la calidad, confort y comodidad que lo representa. Desde sus inicios tuvo soporte de su gobierno, quien le brindo las facilidades para crecer aceleradamente como lo ha logrado en estos años.

En la actualidad Aerolíneas Emirate está ubicada como sexta entre las 10 mejores al nivel mundial. Sin embargo, no todo fue tan fácil, la marca tuvo que pasar por diversos temas políticos para crecer, al igual que busco desarrollar un modelo de negocio de mega centro, que solo le permitía realizarlo en específicos mercados.

Logro posicionarse en los países BRICS y algunos de las Américas. El último éxito es la ruta de NY y Milán.

A continuación, se realizará un análisis más detallado del caso Aerolíneas Emirates y su posible ingreso al mercado peruano. 


\section{CAPÍTULO I: CONTEXTO DE LA EMPRESA}

\subsection{Descripción, antecedentes de la industria y fortalezas de Aerolíneas Emirates}

El caso Emirates es sin duda una historia de éxito global. En tan sólo 25 años la aerolínea se ha convertido en la tercera más grande por capacitad y la más grande por cantidad de pasajeros internacionales, con un crecimiento del 18\% año tras año, según el caso.

Emirates inició sus operaciones en 1985 desde Dubái realizando viajes internos y de pequeñas distancias, contando con 3 aviones que cubrían una breve ruta sobre el desierto de la península arábiga. Desde aquel entonces tuvo como objetivo desarrollar un modelo de negocio basándose en la experiencia del consumidor. Asimismo, lo que más caracterizaba a la marca era tener una flota de aeronaves con mayor innovación en el mercado al que pertenece. Según el libro Fundamentos de Marketing del autor Kotler (2017) “el marketing es un proceso social y administrativo, mediante el cual grupos e individuos obtienen lo que necesitan y desean a través de generar, ofrecer e intercambiar productos de valor con sus semejantes" (p. 5). Lo que Emirates destacaba en sus servicios, ya que todo era en base a lo que podía vivir el cliente durante su estadía en la aeronave, comodidad, confort y un servicio de primera.

En sus inicios, Emirates, se fundó por necesidad del gobierno de Dubái, al no tener desarrollado el mercado de servicio aéreo, por lo que los líderes fueron obligados a lanzar su propia aerolínea. Con el paso de los años, estos fueron su alianza estratégica clave para lograr el éxito que mantiene, realizando servicio de carga al gobierno, siendo una de las ventajas competitivas más fuerte que tenía y lo que generaba temor en las demás aerolíneas con las que competía.

Al analizar el contexto del mercado donde Emirates viene desarrollándose en la figura 1.1 y tabla 1.1, se puede observar en detalle cómo el mercado mundial de servicios de viajes tiene una tendencia positiva de crecimiento con $3.3 \%$ por cada año en los próximos 5 años, actualmente el mercado general es de 2,497.589.9 millones, según cifras oficiales del 2018 de Euromonitor: 
Figura 1.1

Tamaño de mercado global

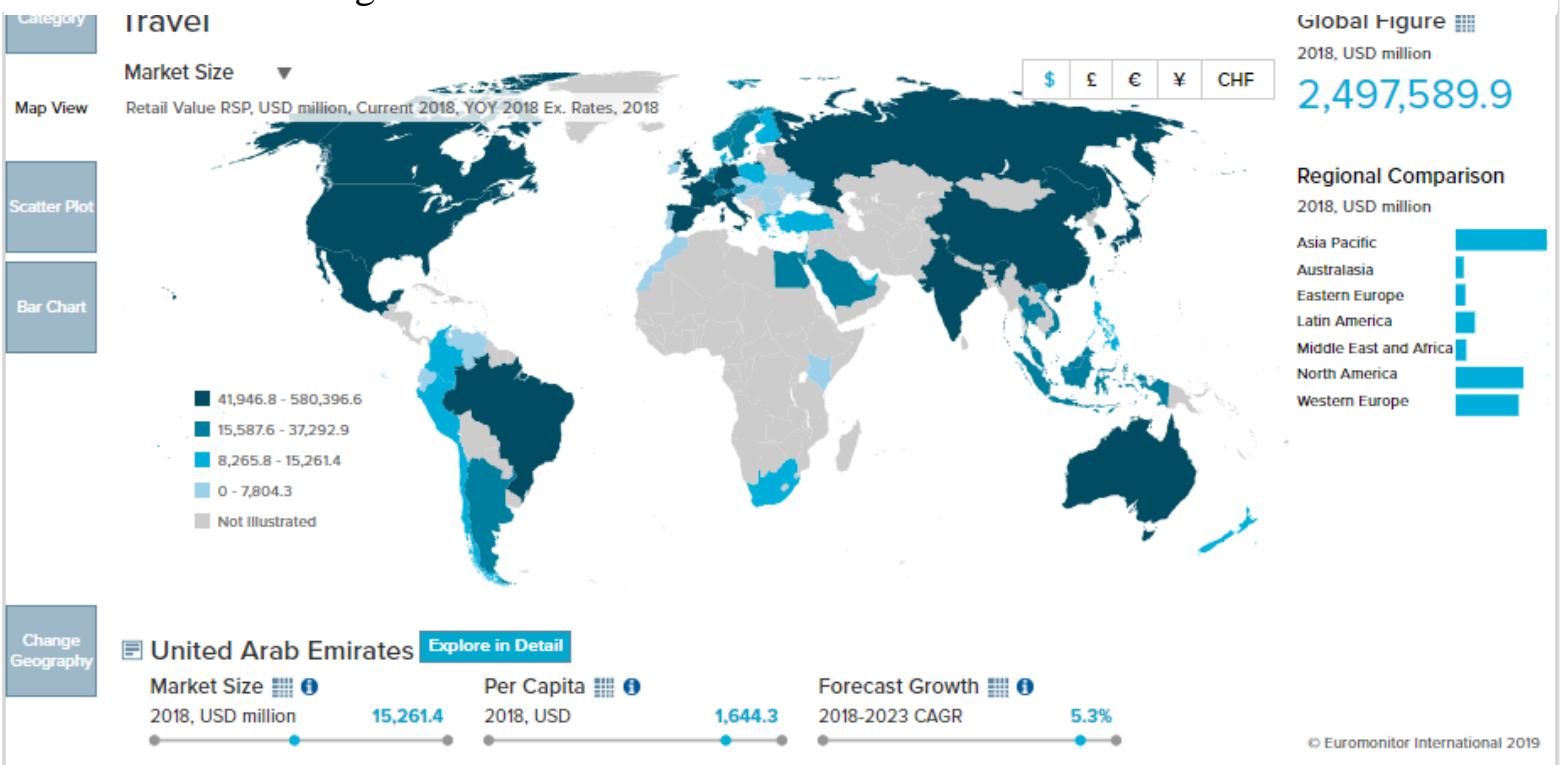

Fuente: Euromonitor (2018)

Tabla 1.1

Crecimiento del mercado global en los próximos 5 años

\begin{tabular}{|l|l|}
\hline Crecimiento Global & $\mathbf{3 . 3 0 \%}$ \\
\hline Asia Pacifica & $4.50 \%$ \\
\hline Australia & $2.80 \%$ \\
\hline Europa Oriental & $4 \%$ \\
\hline Latino America & $4.70 \%$ \\
\hline $\begin{array}{l}\text { Medio Oriente y } \\
\text { Africa }\end{array}$ & $5.20 \%$ \\
\hline Norte America & $2.10 \%$ \\
\hline Europa Occidental & $2 \%$ \\
\hline
\end{tabular}

Fuente Euromonitor (2018)

Elaboración propia.

Para el crecimiento de Emirates, fue clave la planificación de rutas estratégicas, una importante ventaja competitiva de la marca. Esta buscaba captar los mercados marginados con grandes poblaciones, pero con pocas opciones de vuelo, dándole a la aerolínea una ventaja de precursor en diferentes ciudades del Medio Oriente, permitiéndole cerrar el mercado a la competencia y obtener un crecimiento resultante. 
Al respecto en el libro Principios del Marketing de Hoffman (2007) mencionan que "la planeación estratégica se entiende como el plan de acción de la organización que tiene un horizonte de tiempo largo (entre tres a cinco años)" (p. 40). Por lo que nos hace referencia al tiempo en el que Emirates trabajó para lograr su expansión internacional como estrategia de negocio.

Cabe destacar, también, que una fortaleza de la aerolínea era su ubicación estratégica geográfica que le permitió aumentar las ofertas de servicios y crear participación de mercado sobre rutas claves, capitalizando nueva demanda de pasajeros no solo en Europa, sino también en Asia y África, además se adaptó al creciente comercio entre China y África en la década del 2000 beneficiándose con la posición estratégica en la intersección de dos de los flujos de pasajeros más importantes.

\subsection{Análisis interno}

Para realizar un análisis más exhaustivo del caso Emirates, se observará en detalle el valor agregado del producto, personal, mercado, junto con un análisis VRIO.

\section{- Producto}

Desde la perspectiva de Lovelock (2015) en un capitulo íntegramente dedicado hacia la experiencia del cliente con la marca, recurre inicialmente a aspectos de imagen "Una marca ayuda a los mercadólogos a establecer una imagen del servicio en la mente del consumidor, así como a aclarar la naturaleza de la proposición de valor" (p. 88).

El atractivo e imagen de la aerolínea y que lo hacía diferenciarse de los demás es el énfasis que le ponen a la experiencia de servicio Premium, lo que evitó la competencia directa con aerolíneas de bajo costo en lo que refiere al precio, tal como se muestra en la tabla 1.2. Esta experiencia que ofrecían iniciaba desde la visita al aeropuerto, ya que ofrecían compras minoristas libre de impuestos, presentaba innovadoras instalaciones y salas de espera con servicios de spa de lujo para primera clase y business. Durante el vuelo, la experiencia Premium mejoraba aún más, ya que presentaba asientos de clase con comodidades de lujo junto con su nueva flota 
A380, las demás fueron adaptadas para ofrecer suites de primera clase, "spas de ducha" y un bar de servicio completo.

\section{Figura 1.2}

Ingresos por clase de tarifas para el vuelo Dubái- NY de Emirates

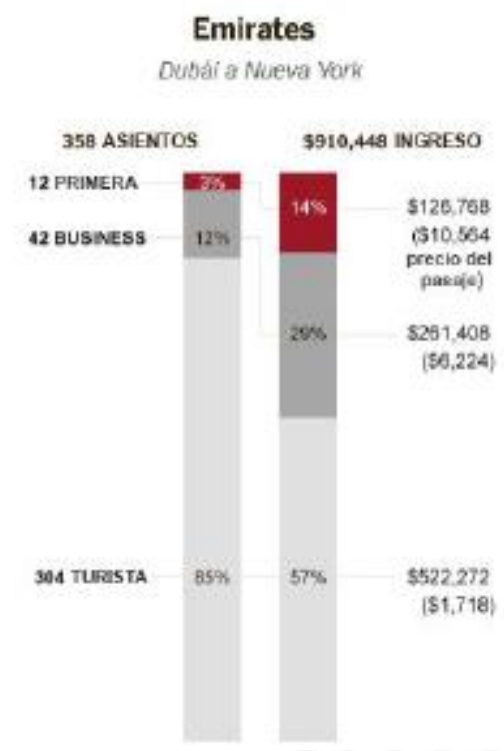

Fuente: Alcacer, J. y Clayton, J., 2019, pp. 29.

Ferrel y Hartline (2012) indicaron:

En el marketing relacional la meta es desarrollar y mantener arreglos a largo plazo, mutuamente satisfactorios, donde el comprador y el vendedor se centran en el valor obtenido de la relación. Siempre y cuando el valor permanezca igual o se incremente es probable que la relación se profundice y se haga más fuerte con el tiempo. (p. 23)

\section{- Personal}

Por el lado del personal, "desempeñan un papel fundamental al anticiparse a las necesidades de los clientes, personalizar las prestaciones de servicios y establecer relaciones personalizadas con los clientes" (Lovelock, 2015, p. 312). 
Es decir, el encuentro con el personal de servicio probablemente sea un aspecto clave para forjar relaciones con los clientes y hacer que la experiencia sea aún más grata.

El equipo de Emirates era una mezcla de diversos orígenes. Contaban con una ética diferente para satisfacer de manera eficaz su diversa base de pasajeros, con tripulantes que sepan hablar diferentes idiomas y que representaban la red de rutas, contemplando no solo las habilidades lingüísticas, sino también culturales.

\section{- Mercado}

Emirates adapto sus estrategias de marketing antes que sus competidores, logrando como consecuencia una ventaja competitiva en el mercado nacional e internacional.

Al expandir el servicio a mercados emergentes y a destinos más lejanos, los analistas de la industria pensaban si continuar con el modelo de negocia mega centro era el correcto. Los pronósticos mostraban un crecimiento sólido en el mercado transatlántico, además de abrirles las puertas a territorio norteamericano, llegando a la ciudad de Nueva York, un éxito que potencialmente podría replicar en otros grandes mercados sujetos a aprobación normativa.

Podemos considerar que "El análisis de la situación del mercado consiste en descomponer la posición actual que la marca tiene en el mercado. Repasa tendencias de la industria por cuanto se refieren a la marca, situación dentro de la propia compañía e información pertinente acerca de los clientes y los canales de distribución existentes" (Hoffman, 2007, pp. 53-54).

\section{- Análisis VRIO}

A continuación, se desarrollará la Matriz VRIO creada por Barney \& Hernerly, la cual analiza los recursos que tiene Emirates, valorados como capacidades y calificados como Valiosos (V), Raros (R), Inimitables (I) y/o parte de la Organización (O) 
Tabla 1.2

Análisis VRIO

\begin{tabular}{|c|c|c|c|c|c|}
\hline RECURSO & Capacidad & $\mathbf{V}$ & $\mathbf{R}$ & I & $\mathbf{O}$ \\
\hline $\begin{array}{l}\text { Producto } \\
\text { innovador }\end{array}$ & $\begin{array}{lcr}\begin{array}{l}\text { Diferenciación } \\
\text { competidores } \\
\text { categoría }\end{array} & \begin{array}{c}\text { de } \\
\text { de }\end{array} & \begin{array}{r}\text { los } \\
\text { la }\end{array} \\
\end{array}$ & $X$ & & $X$ & $\mathrm{X}$ \\
\hline Recurso Humano & $\begin{array}{l}\text { Diferenciación del personal } \\
\text { culturalmente y origen }\end{array}$ & $X$ & $\mathrm{X}$ & & $\mathrm{X}$ \\
\hline $\begin{array}{l}\text { Estrategia } \\
\text { competitiva } \quad y \\
\text { marketing }\end{array}$ & $\begin{array}{l}\text { Dirigirse correctamente al } \\
\text { público objetivo, captación } \\
\text { estratégica del cliente y } \\
\text { desarrollo de fidelidad }\end{array}$ & $X$ & & $X$ & $X$ \\
\hline $\begin{array}{l}\text { Buena relación con } \\
\text { los clientes }\end{array}$ & $\begin{array}{l}\text { Participación en diferentes } \\
\text { auspicios deportivos e } \\
\text { innovación de servicio. }\end{array}$ & $X$ & & & $X$ \\
\hline $\begin{array}{l}\text { Buena relación con } \\
\text { proveedores }\end{array}$ & $\begin{array}{l}\text { Correcta comunicación con } \\
\text { el gobierno }\end{array}$ & $X$ & $X$ & $X$ & $X$ \\
\hline
\end{tabular}

Fuente: Elaboración propia

De acuerdo con las calificaciones obtenidas se puede entender que contamos con un recurso que otorga la empresa una ventaja competitiva, que es lo que se refiere a ser un producto innovador en la categoría.

\subsection{Análisis competitivo}

Santesmases (2012) menciona que desde la perspectiva del marketing "interesa conocer especialmente el efecto que tienen las decisiones de la competencia en la estrategia comercial y en los resultados de la propia empresa”.

Emirates competía con aerolíneas europeas que brindaban transporte de tráfico de pasajeros y de carga. Marcas conocidas en el mercado como British Ariways, Air France, Lufthansa, Iberia, entre otros fueron las principales. Sin embargo, muchas de estas fueron afectadas por la nueva tendencia de las aerolíneas de precios bajos o conocidas como "Low cost", consolidándose con una estrategia de crecimiento, ya que esto impacto desde la experiencia del pasajero hasta la eficiencia del combustible a las marcas. Emirates no se vio 
afectado por dicha tendencia, ya que al ser subsidiado por el gobierno no le afectó al nivel que las otras marcas, dándole una ventaja competitiva muy por encima que las demás.

Sin embargo, había dos marcas adicionales que crecieron al nivel de Emirates con el paso de los años y, a su vez, pertenecían al gobierno local, Qatar Airlines y Etihad; quienes competían en ser "El portal del Medio Oriente" y conectar a los viajeros que iban a otras regiones. Además, buscaban manejar en el pasajero una experiencia Premium durante los trayectos, servicio de alta calidad e instalaciones modernas en el aeropuerto. Por otro lado, también se encontraba otra aerolínea que pertenecía casi al 50\% del gobierno, Turkish Airlines, el cual se convirtió en el protagonista regional significativo como aerolínea de larga distancia.

No obstante, las aerolíneas de competencia buscaban crecer, llegar a diferentes rutas secundaria y mercados emergentes, por lo que las llevo a realizar alianzas estratégicas que Emirates se negaba a formar, ya que consideraba que limitaría el crecimiento de la red y que era inherentemente burocráticas. Emirates se mantuvo firme con su modelo de negocio.

En el Perú, no contamos con aerolíneas con las que pueda competir directamente Emirates, por lo que surgir en nuestro país sería una oportunidad exclusiva de la marca, que ingresaría con la ventaja competitiva frente a las demás de vivir una experiencia Premium en los trayectos ofrecidos.

A continuación, se mostrará en la tabla XX el detalle de los competidores regionales claves donde Emirates se encuentra, quienes presentaban una estrategia similar de experiencia de alta calidad y servicio Premium. 


\section{Figura 1.2}

Resumen competidores regionales claves

\begin{tabular}{|c|c|c|c|c|}
\hline & Emirates & Qatar Airways & Etihad & Turkish Airlines \\
\hline $\begin{array}{l}\text { Centro } \\
\text { principal: }\end{array}$ & Dubái & Doha & Abu Dhabi & Estambul \\
\hline País: & EAU & Catar & EAU & Turquía \\
\hline Población: & 8 millones & 2 millones & 8 millones & 75 millones \\
\hline $\begin{array}{cc}\mathrm{N} .^{\circ} & \text { de } \\
\text { destinos: } & \end{array}$ & 120 & 125 & 86 & 217 (181 intl.) \\
\hline $\begin{array}{cc}\mathrm{N} .^{\circ} & \mathrm{de} \\
\text { aeronaves: } & \end{array}$ & 190 & 127 & 72 & 202 \\
\hline $\begin{array}{c}\mathrm{N} .^{\circ} \\
\text { solicitadas: }\end{array}$ & 230 & 230 & 100 & 187 \\
\hline Fundada: & 1985 & 1993 & 2003 & 1933 \\
\hline $\begin{array}{l}\text { Edad } \\
\text { promedio de la } \\
\text { flota: }\end{array}$ & 6,1 & 5,1 & 4,9 & 6,6 \\
\hline Titularidad: & $\begin{aligned} 100 \% & \text { del } \\
\text { gobierno } & \end{aligned}$ & $100 \%$ del gobierno & $\begin{array}{l}100 \% \\
\text { gobierno }\end{array}$ & $49 \%$ del gobierno \\
\hline
\end{tabular}

Fuente: Alcacer, J. y Clayton, J., 2019, pp. 19.

\subsection{Análisis Externo}

A continuación, se detallan las variables y resultados de las fuerzas Políticas, Demográficas, Económicas, Sociales y Tecnológicas; y su posible impacto en la marca, así como el impacto con la posibilidad de ingreso al mercado peruano. Se califican entonces, como oportunidades o amenazas. 
Tabla 1.3

Análisis del entorno

\begin{tabular}{|c|c|c|c|c|c|}
\hline Fuerza & Variable & Resultado & Impacto & O/A & Fuente \\
\hline \multirow[t]{3}{*}{$\begin{array}{l}\text { Política/ } \\
\text { Legal }\end{array}$} & $\begin{array}{l}\text { Normas } \\
\text { internacion } \\
\text { ales }\end{array}$ & $\begin{array}{lrr}\text { Aparecieron } & \text { políticas } \\
\text { proteccionistas en } & \text { diferentes } \\
\text { países } & & \end{array}$ & Ingreso a nuevos mercados & $\mathbf{A}$ & $\begin{array}{l}\text { Fuente: Caso Emirates: } \\
\text { Conectando lo desconectado }\end{array}$ \\
\hline & $\begin{array}{l}\text { Normas } \\
\text { legales }\end{array}$ & $\begin{array}{l}\text { Elimino los requisitos de visa } \\
\text { para incrementar ingresos con } \\
\text { Emirates }\end{array}$ & $\begin{array}{l}\text { Mayor ingreso de turismo a } \\
\text { Dubái }\end{array}$ & $\mathbf{O}$ & $\begin{array}{l}\text { Fuente: Caso Emirates: } \\
\text { Conectando lo desconectado }\end{array}$ \\
\hline & $\begin{array}{l}\text { Estabilidad } \\
\text { Política }\end{array}$ & $\begin{array}{l}\text { Apoyo incondicional del } \\
\text { gobierno de Dubái facilitando } \\
\text { su crecimiento }\end{array}$ & $\begin{array}{l}\text { Ser una de las tres arolineas } \\
\text { más grandes del Medio } \\
\text { Oriente }\end{array}$ & $\mathbf{O}$ & $\begin{array}{l}\text { Fuente: Caso Emirates: } \\
\text { Conectando lo desconectado }\end{array}$ \\
\hline $\begin{array}{l}\text { Demographi } \\
\text { cal }\end{array}$ & $\begin{array}{l}\text { Crecimient } \\
\text { o población }\end{array}$ & $\begin{array}{l}\text { Un } 88.43 \% \text { de la población de } \\
\text { Emiratos Arabes r con } \\
\text { inmigrantes. Según últimos } \\
\text { datos de la ONU. País con } \\
\text { mayor porcentaje r de } \\
\text { inmigrantes }\end{array}$ & Incremento del mercado & $\mathbf{O}$ & $\begin{array}{l}\text { Fuente: Datos Macro Expansión } \\
\text { (2017). Emiratos Árabes Unidos } \\
\text { registra un incremento de su } \\
\text { población. Recuperado de: } \\
\text { https://datosmacro.expansion.co } \\
\text { m/demografia/poblacion/emirato } \\
\text { s-arabes-unidos }\end{array}$ \\
\hline Social & $\begin{array}{l}\text { Ritmo de } \\
\text { vida }\end{array}$ & $\begin{array}{l}\text { Al interconectar ciudades } \\
\text { dentro de Dubái, la población } \\
\text { tuvo acceso a diferentes lugares } \\
\text { donde antes no llegaba. }\end{array}$ & $\begin{array}{l}\text { Incremento del mercado } \\
\text { potencial. }\end{array}$ & $\mathbf{O}$ & $\begin{array}{l}\text { Fuente: Caso Emirates: } \\
\text { Conectando lo desconectado }\end{array}$ \\
\hline
\end{tabular}

Recopilación de fuentes secundarias debidamente citadas

Fuente: Elaboración propia. 
Tabla 1.4

Análisis del entorno (Continuación)

\begin{tabular}{|c|c|c|c|c|c|}
\hline Fuerza & Variable & Resultado & Impacto & O/A & Fuente \\
\hline \multirow[t]{2}{*}{ Económica } & $\begin{array}{l}\text { Nuevos } \\
\text { mercados }\end{array}$ & $\begin{array}{l}\text { Ingreso a nuevos mercados, ofrecieron } \\
\text { generar nuevas fuentes de ingreso. }\end{array}$ & $\begin{array}{l}\text { Incremento del } \\
\text { Mercado }\end{array}$ & $\mathbf{O}$ & $\begin{array}{lr}\text { Fuente: Caso } & \text { Emirates: } \\
\text { Conectando } & \text { lo } \\
\text { desconectado } & \end{array}$ \\
\hline & $\begin{array}{l}\text { Incremento } \\
\text { economic }\end{array}$ & $\begin{array}{l}\text { Gracias al turismo, la economía en Dubái } \\
\text { fue favorable. }\end{array}$ & $\begin{array}{l}\text { Incremento } \\
\text { inversion }\end{array}$ & $\mathbf{O}$ & $\begin{array}{lr}\text { Fuente: Caso } & \text { Emirates: } \\
\text { Conectando } & \text { lo } \\
\text { desconectado } & \end{array}$ \\
\hline \multirow[t]{2}{*}{$\begin{array}{l}\text { Tecnológic } \\
\text { a }\end{array}$} & $\begin{array}{l}\text { Innovaciones } \\
\text { Aeronáuticas }\end{array}$ & $\begin{array}{l}\text { Varias tendencias como la u 777X y } \\
\text { A380 aparecían en el mercado. }\end{array}$ & Incremento de costo & $\mathbf{A}$ & $\begin{array}{lr}\text { Fuente: Caso } & \text { Emirates: } \\
\text { Conectando } & \text { lo } \\
\text { desconectado } & \end{array}$ \\
\hline & $\begin{array}{l}\text { Nuevas } \\
\text { tendencias }\end{array}$ & $\begin{array}{l}\text { Aparición de aerolíneas Low Cost con } \\
\text { aeronaves de baja tecnología y servicio. }\end{array}$ & $\begin{array}{l}\text { Incremento } \\
\text { competencia }\end{array}$ & $\mathbf{A}$ & $\begin{array}{lr}\text { Fuente: Caso } & \text { Emirates: } \\
\text { Conectando } & \text { lo } \\
\text { desconectado } & \end{array}$ \\
\hline
\end{tabular}

Recopilación de fuentes secundarias debidamente citadas

Fuente: Elaboración propia. 


\section{CAPÍTULO II: DIAGNÓSTICO DEL MARKETING ESTRATÉGICO DE LA EMPRESA}

\subsection{Análisis de estrategia de marketing orientada hacia los clientes}

Emirates es una organización que enfocaba sus esfuerzos hacia el mercado meta, lo que generaba a largo plazo relaciones y fidelidad de los mismos. Para ellos fue importante colocar como prioridad la experiencia que puedan tener los clientes y enfocarse en las relaciones que generen un valor agregado en ellos; así como en los empleados y otros socios. Además, contaba con la capacidad de enfocar los esfuerzos y recursos que mejore la capacidad con la finalidad de mejorar la ventaja competitiva.

"Al crear culturas organizacionales que anteponen a los clientes, las empresas orientadas al mercado tienden a desempeñarse a niveles más altos y a cosechar beneficios de clientes más altamente satisfechos” (Ferrel y Hartline, 2012, p. 51). Desde sus inicios para Emirates el marketing era clave para poder atraer a los clientes y fidelizarlos. Mayormente no todos estaban familiarizados con Dubái y pocos lo veían como un destino turístico. Por ello, la marca empezó a buscar diferentes alternativas en el mercado, hallando la respuesta en algo simple, rentable y altamente visible: el patrocinio deportivo. Si bien fue un buen vehículo de comunicación, el marketing para Emirates era más específico: la experiencia Premium durante el vuelo para su público objetivo, destacando suites, bares en el vuelo, servicios superiores y su tripulación experta y cosmopolita. Impulsando siempre la experiencia superior como ventaja competitiva. Según Euromonitor, Emirates era la marca más valiosa del mundo.

\subsection{Planeamiento estratégico de Marketing}

El plan de marketing tiene varios propósitos, una de ellos es explicar con claridad la forma en la que la organización va a lograr sus objetivos y metas; este, servirá como guía para implementar la estrategia de marketing y para la toma de decisiones que deben tomarse dentro de la organización. 
Emirates anhelaba alcanzar la audiencia masiva y generar consciencia al nivel mundial con los objetivos claros, es por ellos que empezó a planificar y construir las ventajas competitivas que tenía para lograrlo de una manera positiva.

Para tener éxito es necesario que una empresa posea una o más ventajas competitivas que pueda impulsar en el mercado. Esta brinda un beneficio diferencial y superior para satisfacer las necesidades de los clientes o para mantener relaciones con los grupos de interés importantes. Asimismo, cuando estas ventajas están alineadas con las oportunidades, se puede ofrecer al cliente una razón poderosa para que lo elija, sin ella lo más probable es que se convierta en una razón poderosa más en el mercado. Por otro lado, las ventajas competitivas son cruciales debido a que establecen el enfoque estratégico de marketing completo. Tal y como menciona lo citado, Emirates contaba con diferentes ventajas competitivas que lo ayudaban a poder realizar un planeamiento estratégico más rentable y diferenciado.

Para Kotler (2017) la ventaja competitiva es "la medida en que una empresa puede diferenciarse y posicionarse como un proveedor de valor superior al cliente" (p. 184). En caso la aerolínea ingrese al mercado peruano, se posicionaría como una aerolínea diferente frente a las demás. Actualmente un peruano puede disfrutar de la estadía en Emirates, pero saliendo de Lima, sino con conexiones a norte américa o diferentes ciudades donde si está la aerolínea.

\subsection{Descripción y análisis de la estrategia corporativa de la empresa}

Según Hartline y Ferrel (2012) todas las organizaciones:

necesitan una estrategia corporativa, el esquema central o medio para utilizar e integrar recursos en las áreas de producción, finanzas, investigación y desarrollo, recursos humanos y marketing para realizarla misión de la organización y lograr las metras y objetivos deseados. (p. 27)

Gracias a lo mencionado en el párrafo anterior, podemos definir las estrategias corporativas que Emirates estaría desarrollando. Algunas estrategias utilizadas son:

- Desarrollo de Mercado: Una de las estrategias claves de Emirates, era el ingreso a mercados emergentes para expandirse a diferentes ciudades y crecer con mayor 
facilidad. Buscando explotar estos territorios y ampliar su cartera de clientes. Sobre todo, incrementar su presencia en el mercado aeronáutico. Dominguez y Muñoz (2013) mencionan que el desarrollo de mercado es la capacidad de una organización en desarrollar y llegar a segmentos antes no explotados. Tal cual lo estaba realizando la marca.

- Penetración de mercado y diferenciación: Emirates buscaba crear lazos a largo plazo con su público objetivo, al igual que impactar en ellos con el servicio brindado durante los trayectos. Ofreciendo una propuesta diferente con valor agregado, la experiencia Premium para el pasajero. De esta manera tenía como finalidad impactar en ellos y buscar la re- elección para sus próximos viajes. Para esta estrategia Domínguez y Muñoz (2010) indican que la estrategia de penetración aporta al crecimiento de la participación del mercado el cual la marca se dirige.

\subsection{Estrategia genérica}

Porter (1982), conocido como el padre de la estrategia empresarial, estableció 3 estrategias genéricas que ayudan a mejorar el desempeño que la competencia y que pueda haber en el mercado: liderazgo en costos, diferenciación y enfoque.

Liderazgo en costos enfatiza la producción de bienes estandarizados a un costo unitaria muy bajo, con la finalidad de atender a los consumidores muy sensibles al precio a un costo unitario muy bajo, la diferenciación tiene como finalidad producir bienes y servicios considerados únicos en toda la industria y consumidores que son relativamente insensibles al precio, el enfoque se refiere a producir bienes y servicios que cubran las necesidades de pequeños grupos de consumidores. (p.144)

Además, Porter (1982) enfatizó en lo siguiente: las estrategias son tácticas para superar el desempeño de los competidores en un sector industrial; en algunas estructuras industriales significará que todas las empresas puedan obtener elevados rendimientos, en tanto que, en otras, el éxito al implantar una de las estrategias genéricas puede ser lo estrictamente necesario para obtener rendimientos aceptables en un sentido absoluto (p.79). 


\section{Tabla 2.1}

Estrategias genéricas

\begin{tabular}{|c|c|c|c|}
\hline & & Costo más bajo & Diferenciación \\
\hline \multirow{2}{*}{$\begin{array}{l}\text { Ámbito } \\
\text { competitvo }\end{array}$} & Objetivo amplio & $\begin{array}{l}\text { Liderazgo en } \\
\text { costos }\end{array}$ & Diferenciación \\
\hline & $\begin{array}{l}\text { Objetivo } \\
\text { estrecho } \\
\text { (enfoque) }\end{array}$ & $\begin{array}{l}\text { Segmentación de } \\
\text { costos }\end{array}$ & $\begin{array}{l}\text { Segmentación } \\
\text { diferenciación }\end{array}$ \\
\hline
\end{tabular}

Fuente: Porter (1982)

Emirates hace uso de la estrategia de diferenciación y se ubica en el recuadro segmentación de diferenciación, ya que brinda un servicio con experiencias diferentes en el mercado al que pertenece. A su vez, estos son percibidos por su público objetivo, quienes están dispuestos a pagar más por vivir una experiencia diferente en sus trayectos.

Para la marca, ingresar al Perú sería un mercado emergente más en su lista, ya que sería la única que brindaría la experiencia Premium, lo que la diferenciaría de muchísimas aerolíneas que si tienen acceso en nuestro aeropuerto internacional Jorge Chávez.

\subsection{Estrategia competitiva}

Con el paso del tiempo la competencia se intensifica, se vuelve más importante que se distinguen los productos en forma significativa en el mercado. Según el libro de Marketing de Lamb, Hair y McDaniel (2011) menciona la importancia que "se debe de proporcionar y entregar algo único, valioso para los compradores, que vaya más allá que simplemente ofrecer algo a precio más bajo que la competencia” (p. 42).

Por otro lado, Kotler (2017) junto con Ravi Singh, clasifican a las empresas como líderes, retadoras, seguidoras y especializada. Dentro de cada una de estas se cuentan con diferentes estrategias de acción dependiendo de donde se encuentre el producto en el mercado. 
Emirates ingresando al mercado peruano podría considerarse como especialidad en donde se enfoque en un nicho de clientes, ya que ofrece servicios que cuenten con un nivel económico muy superior y con ingresos altos para poder acceder a ellos.

Una vez teniendo definida la estrategia y hacia dónde se va a dirigir, Emirates podría ingresar al mercado con la idea de generar beneficios no solo a los clientes, sino también a nuestro pais y gobierno, por la facilidad de acceso que tendrían otros turistas de ingresar a través de la aerolínea.

Emirates no busca ofrecer sólo el servicio de vuelo, sino una experiencia peculiar, única y Premium, entregarle al cliente un valor agregado y perfecto servicio que sea retribuido por la inversión que realiza para acceder a ella.

De acuerdo a Manuera (2012), la estrategia especialista trata de pequeñas empresas que actúan en zonas específicas con poco atractivo para las grandes empresas, o que destinan sus productos a pequeños grupos de consumidores que no interesan a las empresas más grandes.

Las empresas especialistas conocer mejor al consumidor que otras empresas que atienden a varios segmentos (Manuera, 2012).

\subsection{Estrategia de crecimiento}

Como bien se menciona en el caso, Emirates en tan sólo 25 años desde su fundación logro ser la tercera aerolínea más grande por capacidad y cantidad de pasajeros, esperando aún un crecimiento de $18 \%$ gracias a las nuevas innovaciones aeronáuticas en los siguientes años. Además, al tener como estrategia la planificación de rutas, se observó la oportunidad de ingresar a los países BRICS y en los mercados emergentes en general, dándole la ventaja de ser precursor en distintas ciudades.

En el libro Principios del Marketing, Hoffman (2007) recalca que la empresa debe crear y retener al grupo de clientes y miembros del canal que sean leales, así como a sostener el crecimiento de las ventas el mayor tiempo posible. Para ello, la empresa tal vez invierta en mejorar el producto y en ampliar y esforzar los canales. A medida que el gasto general aumenta para compensar, la ganancia se nivela a medida que se establece (p. 303). 
Lo mencionado por los autores nos quiere decir que Emirates para poder crecer aún más frente a la competencia, debe realizar esfuerzos del marketing con mucho mayor impacto al nivel global.

Ingresando al mercado peruano, de igual manera, debe adaptar sus acciones de marketing de acuerdo a la cultura para lograr un crecimiento optimo como marca que genere el cumplimiento de los objetivos que se tiene con el negocio. Al ser un océano azul para Emirates se tiene certeza que se podrá lograr de manera positiva, ya que se comunicará y demostrará de una manera mucho más adaptada los beneficios de la marca, asimismo, buscará la fidelización como lo viene realizando con otros mercados emergentes a los que ya ha ingresado y ha logrado éxito.

\subsection{Descripción del Brand Equity}

Según Hoffman (2007) el Brand Equity o el capital de marca es el valor de mercado de una marca con base en su reputación y buen nombre. Por otro lado, Kotler (2017) nos explican con mayor detalle la definición: El Brad Equity es el valor añadido de que se denota a productos y servicios. Esta valor se refleja en cómo piensan, sienten y actúan los consumidores respecto a la marca para la empresa. El Brand Equity es un activo tangible para las empresas por su valor psicológico y financiero (p. 174).

De acuerdo a lo mencionado por los autores, podemos describir en detalle lo que hace que Emirates tenga un Brand equity muy bien desarrollado. Gracias a su estrategia de diferenciación, el valor agregado en sus servicios de viaje, las comodidades que brinda desde que el pasajero está en el aeropuerto de Dubái ha tomado mucha relevancia como atractivo y estima de la marca hacia el cliente. A su vez, el auspicio a diferentes equipos deportivos, como lo es el Real Madrid, ha hecho que sea reconocido aún más.

Emirates ha recibido diferentes premios como marca entre ellos esta World Travel Award de la industria de viajes por mejor servicio de primera clase tres veces en los últimos 10 años y obtuvo más de 400 premios de la industria por servicio de aerolínea, pero luego obtendría el premio por mejor aerolínea en general en el año 2013. 
Con esto podemos decir que la marca para el mercado, según los premios y reconocimientos, tiene un alto valor para ellos, buscando ser la aerolínea de elección de muchos pasajeros, algo que se ve reflejado en su crecimiento y en su modelo de negocio.

\subsection{Posicionamiento}

"El posicionamiento de la empresa requiere acciones concretas, no sólo palabras. Si la empresa decide construir una posición sobre la base de una mejor calidad y servicios, primero debe entregar esa posición" (Kotler, 2017, p. 188).

Además, según el libro del autor Philip Kotler (2017) el posicionamiento de un producto es:

el lugar que éste ocupa en la mente de los consumidores en relación con los productos de la competencia (...). El posicionamiento es el arrelgo que se hace para que un producto ocupa un lugar claro distinto y deseable, en relación con productos de la competencia, en la mente de los consumidores meta. Los especialistas del marketing planean posiciones que distingan a sus productos de la marca competidoras y les den mayor ventaja estratégica posible en el mercado meta. (p. 53)

Emirates tuvo como finalidad posicionarse en la mente del consumidor como una marca Premium de servicio con experiencia única viajera en el mercado, lo cual logró con mucho éxito en el mercado. Homs (2011) menciona que "el posicionamiento es la identidad que surge de la esencia de la marca, no se puede ni inventar ni deseñar para adjudicarla a la marca, sino que debe descubrirse dentro de su espíritu" (p. 101). Esto conforma, sobre todo, de valores, beneficios y atributos que competen a la marca y cómo es que quiere ser visto por el mercado.

\subsection{Marketing internacional}

Emirates, es una marca con éxito global, ha logrado interconectar diferentes destinos, atrayendo a nuevos clientes y nuevos mercados. Hoffman (2007) nos mencionan que el marketing internacional "es el proceso que sigue un país para planear y realizar transacciones extra fronterizas con el propósito de hacer intercambios que e cumplen con los objetivos de las personas y las organizaciones" (p.98). 
Sabemos que el ingresar a nuevos mercados internacionales ofrece muchas más oportunidades, ya que no sólo es reconocida a ese nivel, sino que también logra tener un conocimiento más amplio para fortalecer su posición frente a la competencia.

En la elaboración de la estrategia de marketing internacional Santesmases (2012) nos menciona que "se contemplan dos tendencias básicas: la que trata de ajustarse a las características específicas de los mercados extranjeros y la que se basa en la $<<$ globalización〉> de los mercados" (p. 890). A su vez, dicho autor nos define cada una de las estrategias:

- La estrategia diferenciada y/o adaptación: implica un diseño distinto en cada uno de los países al que ingresa, adapta a las características económicas, culturales, etc. Como ventaja principal tiene su efectividad, mejores características y necesidades del mercado. Sin embargo, con el costo más alto.

- Globalización de los mercados y/o estandarización: No implica diferencias de las variables del mercado, las estrategias de marketing son homogéneas, mensajes publicitarios los mismos, sólo traduce lengua según al mercado que se dirige.

Con ambas definiciones podemos resaltar que lo que busca Emirates como estrategia de marketing internacional es realizar esfuerzos de marketing en una estrategia de estandarización, ya que para todos los mercados a los cuales ingresa busca dar el mismo mensaje: servicio con valor agregado y experiencia Premium en los trayectos de los pasajeros.

Con el supuesto de que la aerolínea ingrese al Perú, de igual manera, comunicarían un solo mensaje. Al ser una aerolínea conocida, no afectaría al grado de que nuestro mercado rechace la marca. Sin embargo, esto no aportaría a que la marca tenga una ejecución rígida de la estrategia global. 


\section{CAPITULO III: DESCRIPCIÓN DEL PROBLEMA EN MARKETING OPERATIVO}

\subsection{Marketing Operativo}

Emirates, es una empresa que brinda servicio de transporte vía aéreo, como principal modelo de negocio busca desarrollarse en mercados donde su competencia no tiene acceso, logrando una ventaja competitiva frente a las demás aerolíneas. Para incrementar su participación de mercado, en el análisis del marketing mix la P más importante es la plaza. De igual manera, para ingresar al mercado peruano, Emirates debe buscar establecer un centro de atención en nuestro país.

Para entrar en más detalle del servicio y el marketing operativo que realiza actualmente la marca y debería también realizarlo en Perú se va a entrar en detalle para conocer mejor el negocio.

\subsection{Descripción de servicio}

El servicio que brinda Emirates como aerolínea son dos. El primero y principal es el transporte aéreo de pasajeros a diferentes ciudades de Europa, Norteamérica, Medio Oriente, entre otros; este servicio busca generar experiencias, ya que brinda no sólo la salida y entrada a otros países, sino que también tiene como finalidad que el vuelo sea cómodo e inolvidable. El segundo servicio que brinda es a su fundador, el gobierno de Dubai, realizando transporte de carga. Este último es su principal motor y soporte de la aerolínea, ya que lo subsidia en diferentes costos que evita que realice la marca, apoyando al ahorro e inversión de la misma.

Lovelock (2015) nos define que "la naturaleza del producto sirve para determinar cuáles servicios complementarios se deben ofrecer y cuáles podrían ser útiles para aumentar el valor y lograr que los intercambios con la organización resulten más fáciles" (p. 77). En general, toda clase de servicio que pueda brindarse en el mercado tiene complementarios, ya se servicio post compra, entre otros. Esto veremos en detalle en el siguiente punto. 


\subsubsection{La flor de los servicios complementarios}

Los servicios complementarios tienen ocho grupos que forman los pétalos que rodean el centro de una flor, a la que llamamos la "flor del servicio", en una organización de servicio bien diseñada y manejada, los pétalos y el centro mantiene su frescura y forma. Un servicio mal diseñado o de pobre ejecución es como una flor a la que le faltan pétalos, lo tiene marchitos, descoloridos (Lovelock, 2015).

Este diagrama donde se muestran los servicios complementarios que puede ofrecer una empresa y que agregan valor a los clientes. Por otro lado Hoffman (2007) menciona de ocho variables que representan servicios que se deberían ofrecer y cuáles podrían ser útil para mejorar el servicio.

Figura 3.1

La flor del servicio

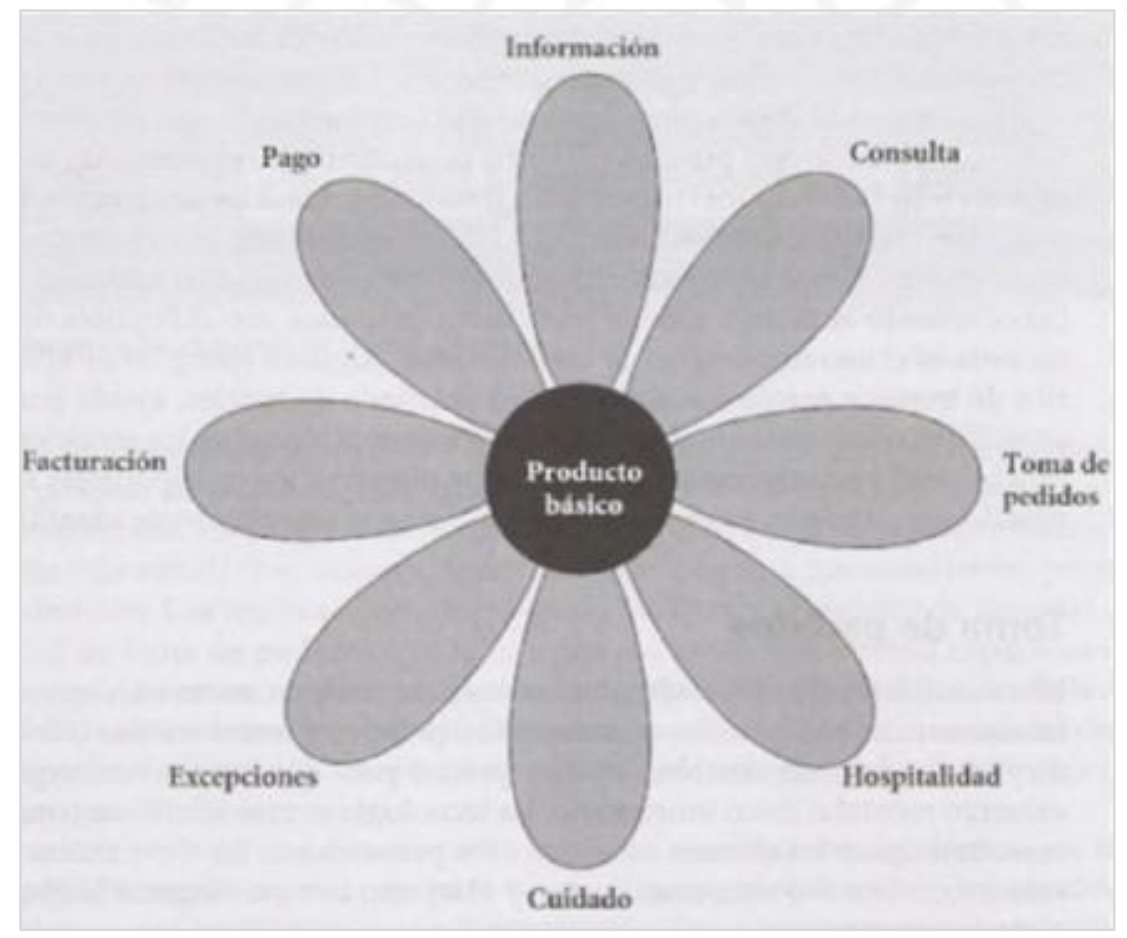

Fuente: Lovelock (2015)

En Emirates se encuentran los siguientes atributos para cada pétalo:

- Información: Los usuarios y/o pasajeros tienen acceso a información que necesitan saber de la aerolínea, ya sea vuelos, horario de vuelos, horarios de atención, destinos, 
fechas, precios, peso equipaje, cantidad de equipaje, servicios que brindan, modo de pago, detalle del servicio de viaje, entre otros, esto gracias a la página web de la misma aerolínea, www.emirates.com.

- Consulta: El cliente tiene acceso a solucionar diferentes dudas que pueda tener en la misma página web, así como tendrá acceso a correos electrónicos, App de la misma aerolínea para poder resolver sus dudas.

- Toma de pedido: En este caso sería la compra de pasajes, el cual se puede realizar a través de la misma página web de la aerolínea y/o también en diferentes páginas terceras oficinales que tienen ofertas de vuelos como por ejemplo Despegar. De igual manera, el usuario tendrá acceso a las diferente App de sus Smartphone, donde también podrá adquirir sus pasajes.

- Hospitalidad: Adicional a realizar el servicio de transporte, Emirates busca que los pasajeros tengan una hospitalidad Premium, de confort y comodidad destacable. Es por ello que los aviones que esta marca cuentan con un diseño único que considera las necesidades de su mercado, además cuenta con diferentes servicios de bar y spa en sus instalaciones dentro del avión para que sea de uso del pasajero durante el vuelo.

- Cuidado: Este pétalo es uno de los más importantes y primordial para la marca, ya que todos los servicios que puedan brindar la aerolínea deben estar regulados y de acuerdo a las políticas regulatorias de aeronaves internacional, así como también la protección e implementos en caso de accidentes para los pasajeros. Es ahí donde se percibe la confianza hacia la marca, lo que aporta con la fidelización por parte de los clientes.

- Excepciones: Emirates busca tener este procedimiento definido para que pueda responder con eficacia los reclamos, sugerencias y elogios por parte de los usuarios. Expresando su nivel de satisfacción durante el viaje, para que se pueda tener una respuesta correcta con rapidez.

- Facturación: En el perfil de la misma página se podrá ver en detalle las compras de pasajes que realiza, de igual manera, al registrar el correo electrónico una vez ya comprado el pasaje se recibirá un mail detallando precio e impuestos de la nación a la que pertenece. 
- Pago: El pago se puede realizar de dos maneras, una de ellas y la principal es mediante la página web principal y los aplicativos de la aerolínea, por otro lado, también se puede manejar por depósito bancario. Este último ya casi se ha vuelto obsoleto, por las innovaciones que existen en el internet.

\subsubsection{Precio}

\subsubsection{Política de Precio}

Nagle (2002) menciona que:

la diferencia entre la fijación de precios y la fijación estratégica de precios es la misma que la diferencia entre accionar a las condiciones del mercado o actuar activamente frente a ella, esta es la razón por la que las empresas con cuotas de mercado y tecnología similares obtienen a menudo recompensas muy distintas por los esfuerzos. (p. 1)

Cuando hablamos de servicios, los clientes presentan en el camino distintas dificultades para determinar la calidad antes de adquirirlo. Por lo que la fijación de precios es fundamental, ya que puede ser la única señal de calidad disponible antes de la experiencia de compra. Si los precios son demasiado altos, puede generar expectativa y precepciones (Ferrel y Hartline, 2012)

Emirates fue subsidiado por el gobierno desde sus inicios, omitiendo el pago de diferentes costos que normalmente asume una compañía aérea, como lo son: el pago de combustible, omisión de impuestos, entre otros. Por lo que los únicos costos que manejaban era por adquirir nuevas aerolíneas y esfuerzos de marketing para hacerse conocido de manera global. A pesar de no asumir lo mencionado, Emirates manejaba una lista de precios para los pasajes muy por encima que las demás aerolíneas, ya que manejaban una política de precio basado en el valor del cliente, la experiencia Premium, y todo lo que los servicios de confort durante el trayecto.

Según el libro de Marketing de Servicios de Lovelock (2015) señala que:

una estrategia de fijación de precios se puede describir como un trípode, donde los costos del proveedor, la competencia y el valor para el cliente son tres pies de una silla, los costos que una empresa necesita recuperar 
generalmente imponen un precio mínimo, o piso, para una oferta de servicio específico, y el valor que percibe el cliente de la oferta establece un precio máximo o techo. El precio determinado por la competencia se encuentra dentro del rango mínimo y máximo. (p.129)

Actualmente si un peruano desea realizar un viaje a través Emirates, los precios superan los \$2,000 (Emirates, 2019), a pesar de que el viaje no se realiza 100\% con la misma aerolínea, ya que al no llegar a nuestro aeropuerto realiza conexiones con JetBlue hacia las ciudades donde si ingresa la marca, se podría considerar que el precio está por encima del promedio de compra que maneja un peruano, según últimos estudios, el gasto promedio es de $230 \$$ por viaje, optando más por destinos nacionales como ahorro para ellos ("Los peruanos gastan un promedio de USD $\$ 230$ por viaje”, 2019). No obstante, sabemos que si existe un nicho de mercado que estaría dispuesto a adquirir el servicio de Emirates (ejecutivos, personas clase A+, managers, entre otros). Podríamos calcular que el precio de los pasajes para vuelos directos estaría alrededor de un $40 \%$ adicional, considerando que Jetblue es una empresa "Low Cost" conocida en el mercado como tal.

Kotler (2017) en su libro Marketing menciona:

los costos establecen el límite mínimo del precio, pero la meta no reducir siempre los costos al mínimo. De hecho, muchas empresas invierten en costos más altos para poder cobrar precios más altos y lograr mayores márgenes de ganancia. La clave está en determinar la distribución de costos y precios, es decir, en determinar cuánto gana la compañía por el valor que entrega a sus clientes. (p. 305)

Cabe mencionar que Emirates sería la primera aerolínea que ingresa al mercado peruano con este nuevo concepto Premium, por lo que no contaría con una competencia 100\% directa y los precios a los que podrá acceder los pasajeros son de aerolíneas estándares y de low cost. 


\subsubsection{Estrategia de Precio}

Ferrel y Hartline (2012) mencionan que, desde la perspectiva de un comprador, hay dos temas claves para a estrategia de fijación de precio para la mayoría de empresas :1) valor percibido, y 2) sensibilidad a los precios. Además, los autores mencionan que:

los beneficios del cliente incluyen todo lo que éste obtiene de la oferta de producto, como calidad, satisfacción, prestigio/imagen y la solución de un problema. Los costos del cliente incluyen todo lo que debe ceder como dinero, tiempo, esfuerzo y todas las alternativas no seleccionadas. (p. 233)

Por sobre todas las cosas, Emirates se centra en el cliente con la finalidad de brindarle a los pasajeros nuevos destinos, valor agregado en sus viajes y creando experiencias satisfactorias, por lo que su estrategia de precio es descreme, ya que se trabaja para que los pasajeros perciban a la marca como uno con ventajas únicas, de alta calidad y difícil de imitar, frente a las demás aerolíneas del mercado, por ello se busca atraer a la mayoría de público dispuesta a pagar por satisfacción y comodidad. Para este caso, Nagle (2002) menciona que:

para descremar un mercado está diseñado para conseguir márgenes elevados renunciando a un elevado volumen de venta (...). Por lo tanto, esta estrategia solo es viable cuando el beneficio de vender un segmento insensible al precio supera el de vender a un mercado mayor a precios menores. (p. 176)

Con lo mencionado por el auto y los datos brindados en el caso de estudio, podemos destacar que los clientes están dispuestos a para altas tarifas por un servicio de alta calidad y de beneficios diferenciados. De igual manera, los clientes podrán apreciar los precios de cada uno de los destinos a los que llega la aerolínea a través de sus diferentes canales de comunicación, la página web, App y diferentes páginas de vuelos oficiales.

\subsubsection{Plaza}

\subsubsection{Estructura del canal}

Según Ferrel y Hartlines (2012) existen 
muchas opciones estratégicas para la estructura de un canal de marketing, pero con frecuencia complejas y muy costosas de implementar (...). Encontramos tres opciones estructurales básicas para la distribución en términos de cobertura del mercado y nivel de exclusividad entre proveedor y el minorista: distribución exclusiva, selectiva e intensiva. (p.270)

En la tabla 3.1 se puede ver a detalle la definición de cada una de estas estrategias

\section{Tabla 3.1}

Estrategias de distribución

\begin{tabular}{|c|c|c|}
\hline \multicolumn{3}{|l|}{ Estrategia de distribución } \\
\hline Exclusiva & \begin{tabular}{|l|} 
Selectiva \\
\end{tabular} & Intensiva \\
\hline $\begin{array}{l}\text { Más restrictivo de cobertura } \\
\text { del mercado, conceden } \\
\text { derecho único de ofrecer el } \\
\text { producto en una región } \\
\text { geográfica definida. Esto se } \\
\text { asocia más a productos con } \\
\text { imagen de prestigio, } \\
\text { empresas que intentan dar } \\
\text { una imagen exclusiva o de } \\
\text { prestigio. Estos solo se } \\
\text { enfocan en un solo } \\
\text { segmento del mercado bien } \\
\text { definido, los clientes están } \\
\text { dispuestos a buscar el } \\
\text { producto, cueste lo que } \\
\text { cueste, dado el prestigio o } \\
\text { valor único a la marca. }\end{array}$ & $\begin{array}{l}\text { Recurren a esta modalidad } \\
\text { ofrecen varios } \\
\text { comercializadores el } \\
\text { derecho de vender producto } \\
\text { en una región geográfica } \\
\text { definida. Brinda a los } \\
\text { clientes oportunidad de } \\
\text { comparar, recolectar } \\
\text { información de precios, } \\
\text { comparar tiendas y usar } \\
\text { diversidad de medios de } \\
\text { pago y obtener el que } \\
\text { desean. En este caso } \\
\text { permite al fabricante tener } \\
\text { más control sobre los } \\
\text { precios, exhibición y } \\
\text { técnicas de venta. }\end{array}$ & $\begin{array}{l}\text { Esta estrategia pone a un } \\
\text { producto a disposición de } \\
\text { máximo numero de } \\
\text { comerciantes } \\
\text { establecimientos en cada } \\
\text { área con el fin de ganar } \\
\text { mucho más exposición y } \\
\text { oportunidades de venta } \\
\text { como sea posible. Esta } \\
\text { estrategia mejora la } \\
\text { alternativa para el producto } \\
\text { de conveniencia. Este tipo } \\
\text { de distribución se usa más } \\
\text { cuando se habla de } \\
\text { productos de consumo } \\
\text { masivo. }\end{array}$ \\
\hline
\end{tabular}

Fuente: Elaboración propia. Con información extraída del libro "Estrategias de Marketing” p.271. 
Emirates cuenta con 148 destinos en África, las Américas, Asia, Europa, Medio Oriente y el Pacifico; tal y como lo muestra la figura xxx, en cada uno de ellos cuenta con una oficina directa de la marca donde brindan información y servicios exclusivos. Por lo que la distribución que le compete a la marca es exclusiva, ya que las sedes tienen el derecho de ofrecer el servicio en cada región en la que se encuentra. Como bien sabemos, la marca se enfoca a un segmento de mercado más Premium y con un nivel adquisitivo superior, a su vez, estos lo perciben como un valor único de la marca, por lo que la marca influye en su mayoría en la fijación de precios a un grado más alto.

\section{Figura 3.2}

Ubicación de sedes al nivel mundial de Aerolíneas Emirates

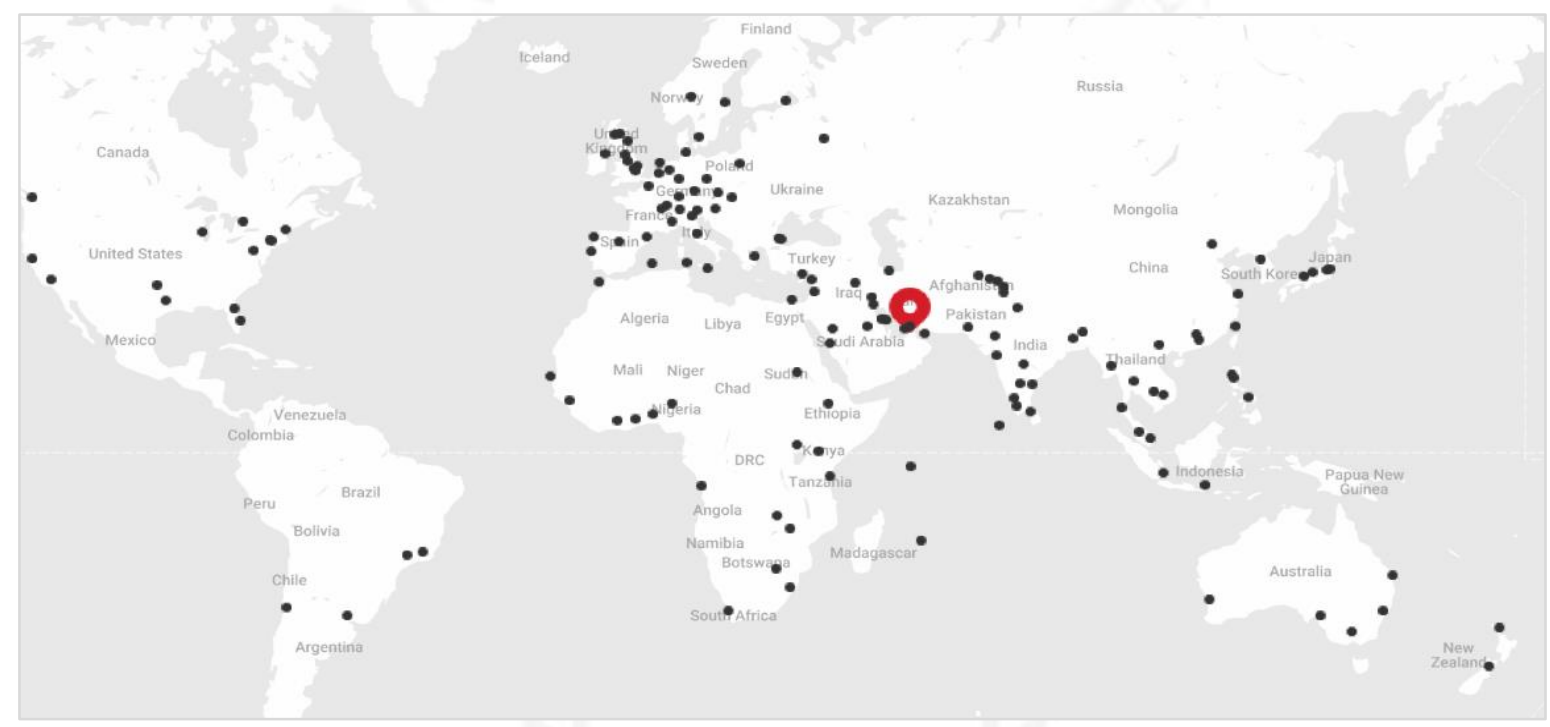

Fuente: Aerolíneas Emirates (2019)

\subsubsection{Comunicaciones integradas}

\subsubsection{Detalle y descripción de actividades de comunicación}

Emirates Airline, afirmó que iniciar un vuelo directo hacia Lima sería muy bueno para el mercado peruano y sus vecinos. No se descarta que en un futuro cercano pueda concretarse esta operación. Sin embargo, primero es la necesidad de evaluar el mercado en detalle. ("Emirates Airline no descarta volar a lima en un futuro cercano", 2011) Tal y como se menciona en líneas anteriores el ingreso de la marca aportaría en la economía al mercado 
peruano de manera positiva, por el gran conocimiento que se tiene de la marca al nivel mundial. Es por ello que se ve conveniente realizar actividades de comunicaciones integradas de acuerdo al negocio como publicidad en diferentes revistas de alta gama, páginas exclusivas de clase ejecutiva, relaciones públicas de lanzamiento como eventos cocktail, mantenimiento como activaciones BTL en el aeropuerto internacional Jorge Chávez y presencia o auspicio en eventos del segmento de NSE A+.

Las comunicaciones de marketing de cada elemento, de la mezcla promocional (venta personal, publicidad, promoción de ventas y relaciones públicas) se deben de integrar, ya que el mensaje que llegue al consumidor debe ser el mismo sin importar el medio que se utilizará (Lam, Hair y McDaniel, 2011).

La estrategia promocional debe estar relacionada estrechamente con el proceso de comunicación, esta debe transmitir un solo mensaje como un todo, por ello es importante que a través de todos los medios que una empresa gestione este papel de la empresa (Lam, Hair y McDaniel,2011).

A continuación, se detallará las actividades y presencia de la marca en diferentes medios.

\section{- Publicidad en redes sociales:}

Emirates Airlines cuenta con páginas en las diferentes plataformas que en la actualidad cuentan con un tráfico de usuarios muy alto, como lo es Instagram y Facebook, por lo cual se invierte constantemente para llegar aún más al público objetivo y poder lograr tener un posicionamiento en el mercado de aerolíneas, además estas páginas permiten crea y contratar publicidad de manera sencilla y económico. La finalidad es que el usuario busque información adicional, le de "like" al fan page en ambos medios y conozca los servicios que ofrece para que se sienta atraído por la marca

Crear páginas mejoran productividad, permiten hacer negocios y facilitan la práctica del marketing (Caballar, 2012)

Los elementos gráficos se pueden observar en detalle en la figura 3.3 y figura 3.4 
Figura 3.3

\section{Página oficial en Instagram}

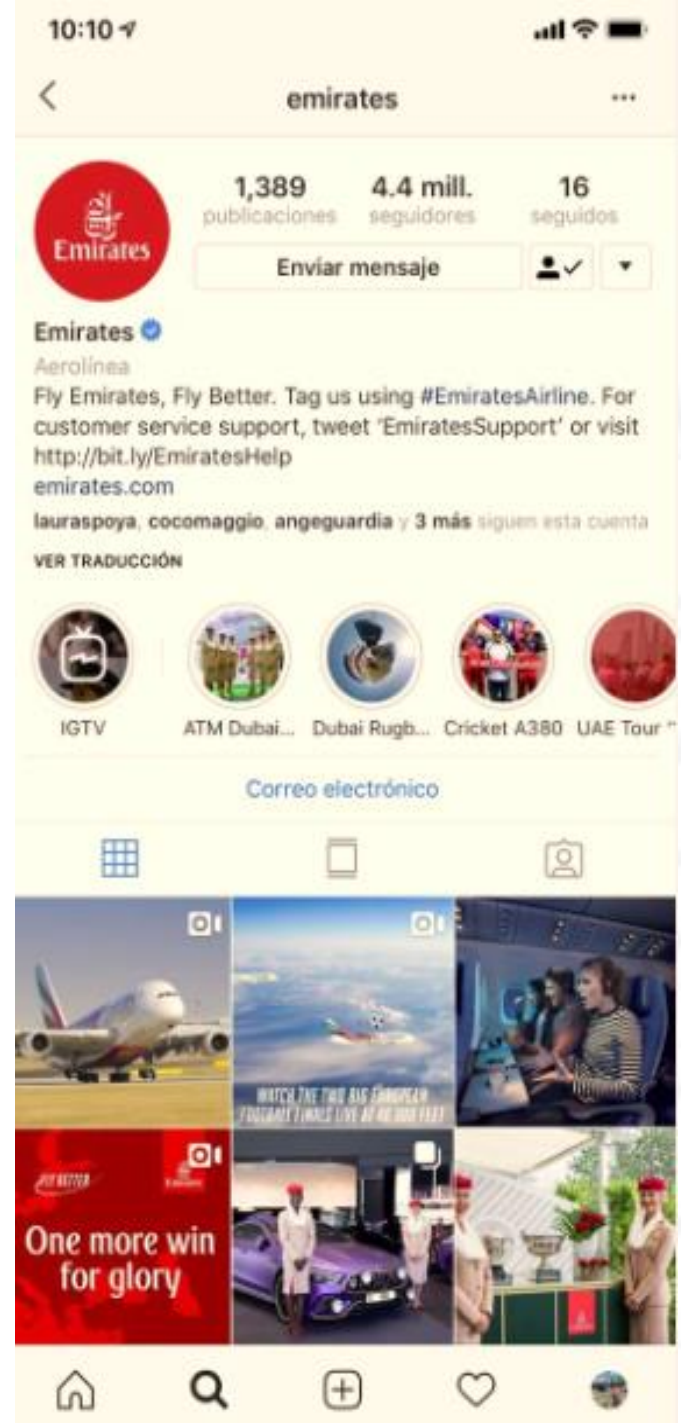

Fuente-Aerolinea Emirates (2019) 
Figura 3.4

Página oficial en Facebook

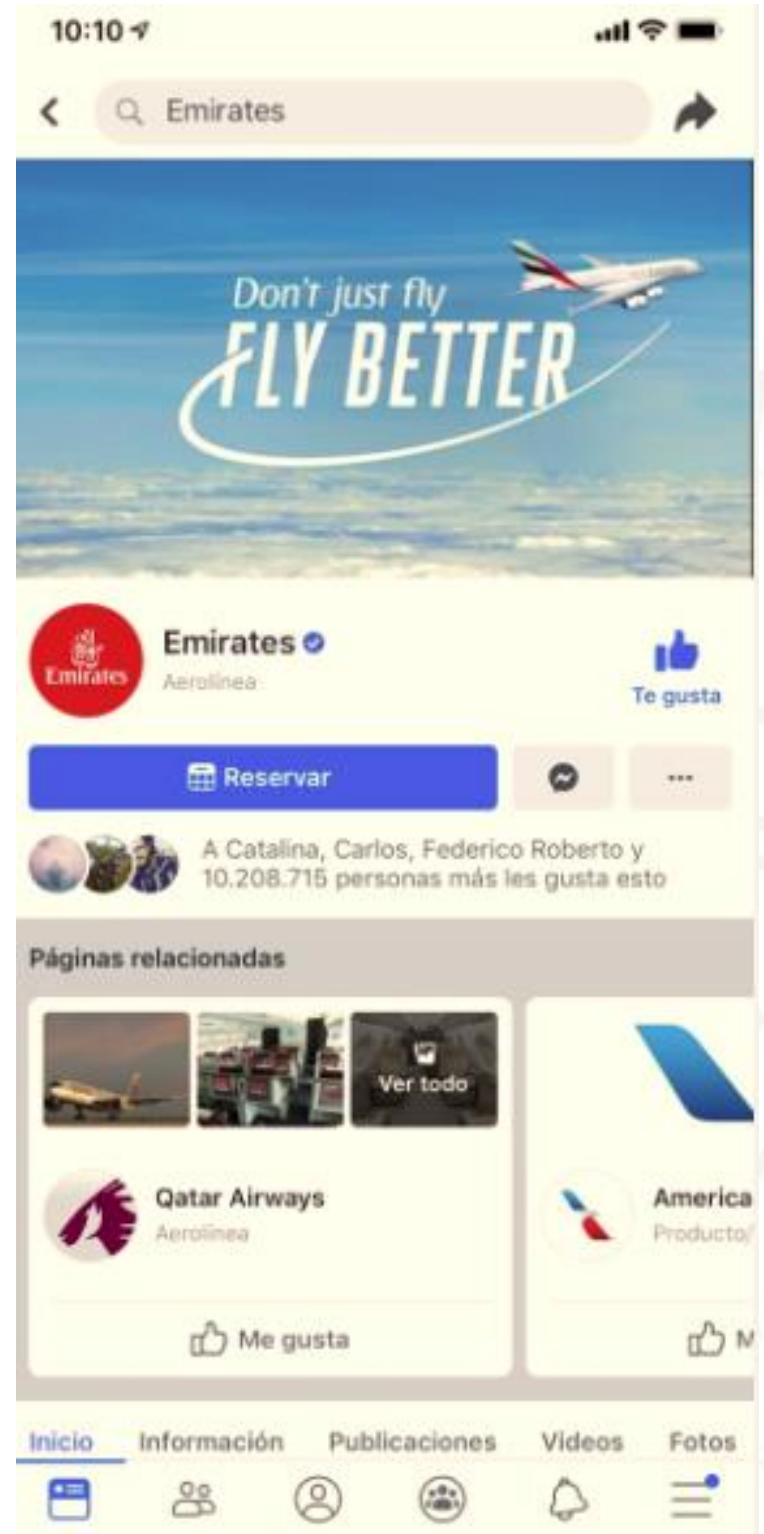

Fuente: Aerolinea Emirates (2019) 


\section{- Relaciones públicas de lanzamiento en Perú; activaciones BTL y presencia en eventos exclusivos}

Para que pueda llegar con mayor facilidad al NSE más alto y exclusivo del país, Emirates Airlines, podría participar en diferentes eventos importantes como auspiciador y/o realizando una activación de marca. Donde tenga la finalidad de conocer los servicios que brinda Emirates a mayor detalle y manifestar los valores de la marca de una manera más dinámica, entendible y clara.

La realización de las actividades especiales que realice la empresa en el mercado meta se hace presente a través de eventos promocionales masivos, dependiendo al sector que se dirige. Estas sirven para informar que hay un servicio en el mercado, indica para que sirve, manera de uso, beneficios al usarlo, donde adquirirlo y facilidades de hacerlo (Pietro Herrera,2010).

\subsubsection{Publicidad}

En el caso nos mencionan la manera en la que Emirates Airlines busca tener mayor impacto al nivel global, a través de auspicio en los deportes, implementando una estrategia de publicidad en donde la consecuencia fue una aceptación positiva en el mercado.

Según el libro de "Principios de Marketing y sus mejores prácticas" las empresas pueden agregar valor a sus ofertas recurriendo a tres caminos básicos: innovar, mejorar la calidad o modificar las percepciones del consumidor. Estos tres elementos de valor agregado son independientes. La publicidad agrega valor a las marcas, de igual manera, influye en las percepciones del mercado el cual me quiero dirigir (Hoffman 2007).

Se tiene mapeado que Emirates Airlines realiza publicidad online mediante sus redes sociales oficiales como Facebook e Instagram, en donde muestra el logo, la marca y mensajes que llaman la atención del usuario con el objetivo de motivar la compra de pasajes a través de la aerolínea. Adicional muestran publicidad de diversos destinos a los que pueden llegar los clientes, así como también imágenes de los equipos internacionales que auspicia con diversos mensajes motivacionales para ellos y de las instalaciones de los aviones. 


\subsubsection{Proceso}

\subsubsection{Flujograma del servicio}

\section{Figura 3.5}

\section{Flujograma del servicio}

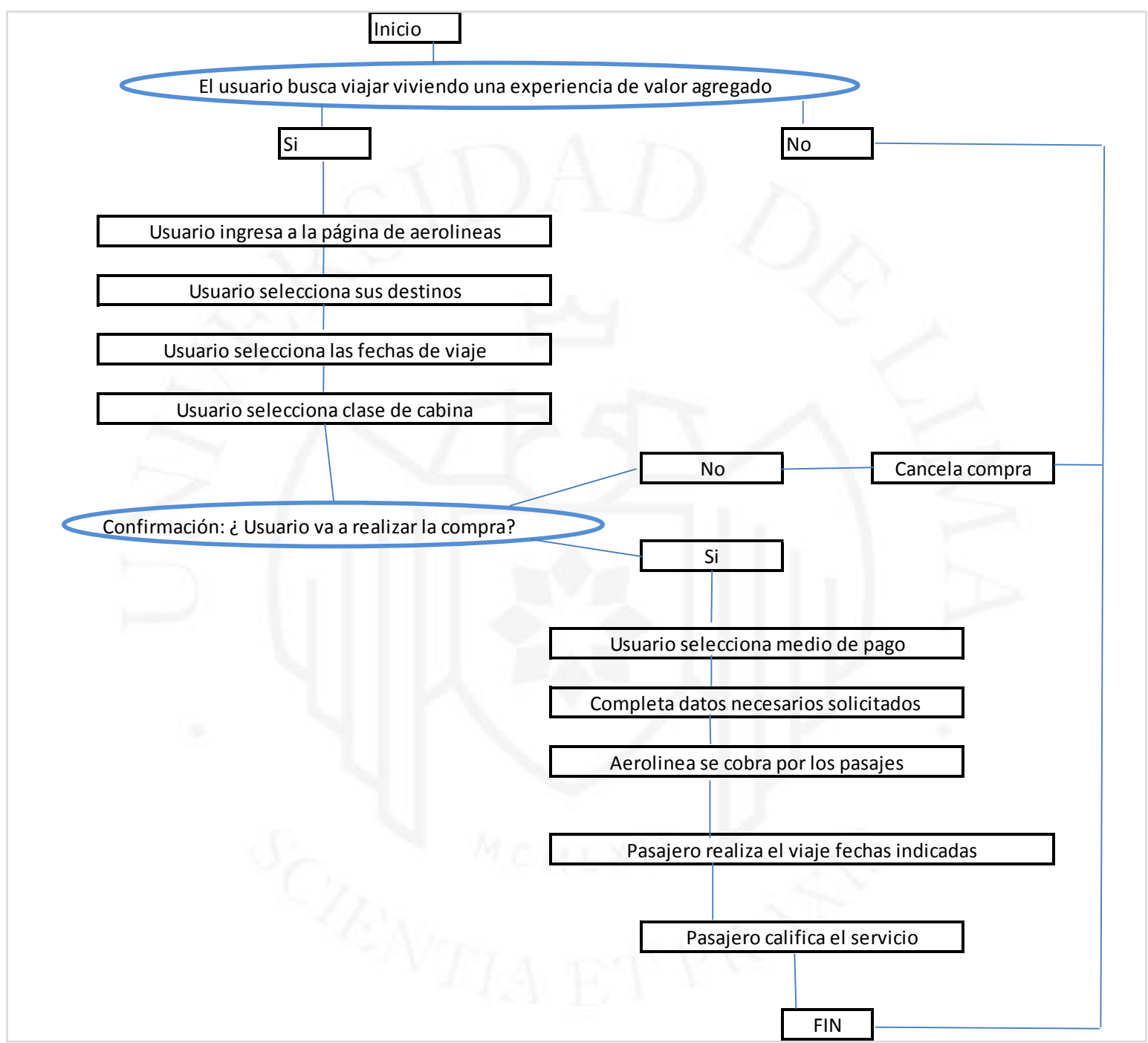

Fuente: Elaboración propia. 


\section{CAPITULO IV: GESTIÓN Y PROCESO DE VENTAS}

\subsection{Canales de distribución}

Respecto a los canales de distribución que tiene que mantener y crear Emirate Airlines, hay que considerar el análisis de Hoffman (2007): “Un canal de marketing, también llamado canal de distribución, es una red de organizaciones que crean utilidad de tiempo, utilidad de jugar y utilidad de posesión para los consumidores y usuarios comerciales” (p. 352)

Emirates cuenta con hasta 3 niveles de dimensiones en su estructura del canal de marketing, como se muestra en la figura 4.1

Figura 4.1

Distribución e intermediarios
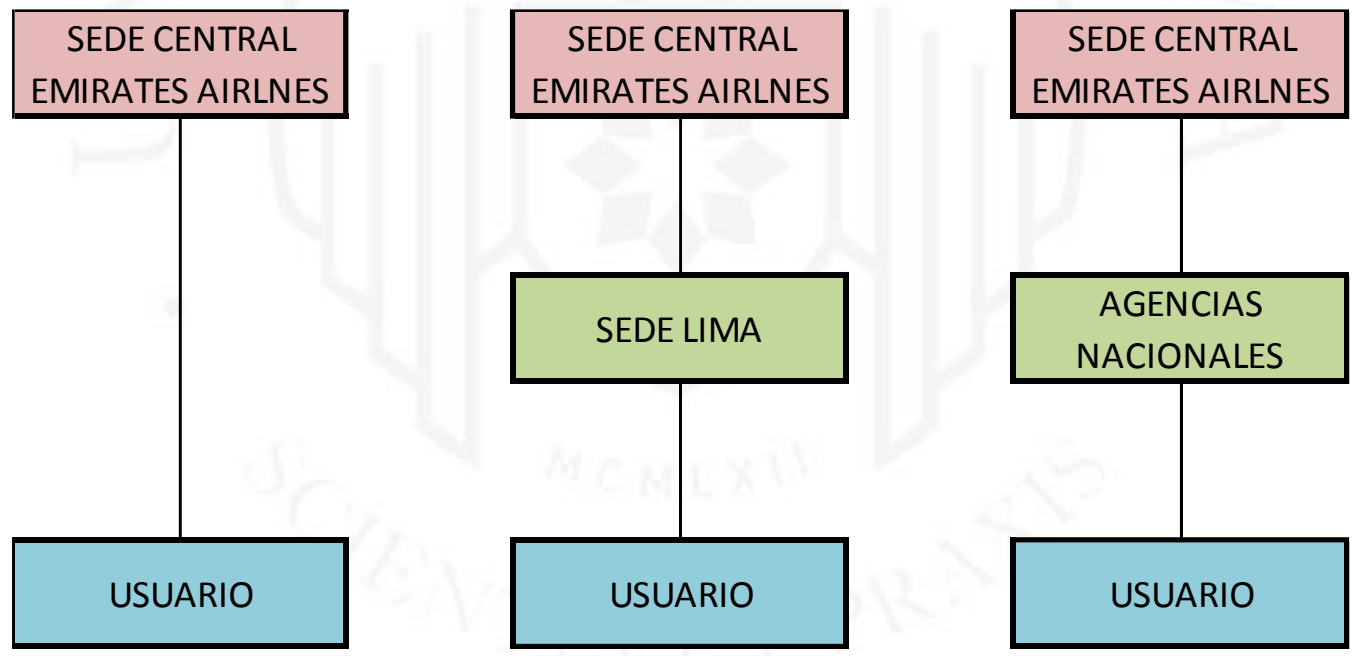

Fuente: Elaboración propia

Ingresando en el mercado peruano la aerolínea contaría con 3 niveles específicamente, ya que la oficina en Lima sería el intermediario para venta de pasajes con la oficina central en Dubai y/o la de Brasil que maneja América Latina ("Emirates Airline no descarta volar a lima en un futuro cercano", 2011), al igual que diferentes agencias de viajes que tenemos actualmente en el mercado. 


\subsection{Gestión de trade marketing}

Para la definición de trade marketing Victoria Labajo (2011) menciona que "se entiende como una visión global del negocio que persigue satisfacer las necesidades de beneficio que tienen la distribución y la fabricante. Para conseguirlo, este tipo de marketing desarrolla las siguientes funciones: previsiones y planes de venta, control de presupuesto de ventas, análisis del cliente y gestión de categoría, además, de servir de puente entre Marketing y Ventas” (p. 45).

Emirates Airlines tenía como objetivo satisfacer las necesidades de su público objetivo dando un valor agregado diferenciado que su competencia, por ello desarrollo un plan promocional en su canal dirigido al cliente, este se comunicó en los diferentes medios públicos, así como también deportivos. En Perú es necesario realizar un estudio de los hábitos de compra para conocer a más detalle donde, cuándo y por qué el peruano realizaría la compra de pasajes vía Emirates. Con esta información se puede dirigir todos los esfuerzos del marketing en el trade de manera óptima y en el canal adecuado dependiendo el NSE y costumbres del consumidor.

Es importante reconocer que el trade marketing busca mejorar el servicio de una manera más especializada, al igual que tener un control sobre lo ofrecido en el mercado. Además este concepto ayuda a que pueda generarse volúmenes de venta en caso haya algún problema en el canal donde se encuentra la marca. Emirate Airlines tiene una oportunidad grande en el desarrollo de trade marketing en el Perú, a pesar que seamos uno de los más pequeños de America Latina, contamos con un gran potencial de crecimiento económicamente que aportaría de manera positiva el ingreso de la marca ("Emirates Airline no descarta volar a lima en un futuro cercano", 2011).

\subsubsection{Funciones de trade marketing y soporte}

Diaz (1996) nos define cinco funciones fundamentales del trade marketing:

- Construir la base de datos con clientes, motivaciones, actividad promocional de competencia

- Crear planes para alcanzar los objetivos de la marca por sectores de distribución 
- Identificar oportunidades de volumen

- Desarrollar caminos creativos para conseguir volúmenes a través de promociones

- Asegurar que toda actividad este analizada y evaluada

Con la ampliación del aeropuerto internacional Jorge Chávez, Emirate Airlines tendría la oportunidad de poder establecer un canal directo hacia los clientes, donde pueda brindar diferente tipo de información acerca de los servicios, y, de igual manera, realizar diferentes esfuerzos del marketing en el trade para poder generar venta en el punto. Esta obra beneficiaria el ingreso de la marca, ya que aportaría con la creación de un punto de venta directo de venta de la aerolínea en Perú como soporte a la marca.

Lo ideal es que este punto siga con el modelo de negocio que maneja internacionalmente, con las comodidas, el confort y el valor agregado de la experiencia Premium con la finalidad de atraer de una manera más creativa al cliente peruano a realizar la compra y re-compra. 


\section{CAPITULO V: ANÁLISIS DE RESULTADOS}

Aerolíneas Emirates ha logrado posicionarse en el mercado internacional como una de las marcas más importantes de su mercado aeronáutico. Además, su estrategia de ingreso a mercados emergente aporto a las interconexiones y a su crecimiento. Sin duda, la aerolínea es un claro ejemplo de éxito al nivel mundial, ya que a pesar de muchas tendencias amenazaron su crecimiento, nada lo pudo impedir.

Hasta el 2013 ha sido la 3ra aerolínea más grande por capacidad y la más grande por cantidad de pasajeros internacionales. Actualmente, según la revista Cosas ("Las 10 mejores aerolíneas para viajar en el 2019”, 2018), Aerolíneas Emirates es considerada como la 6ta aerolínea mejor para viajar entre las 10 más importantes al nivel mundial.

La oportunidad de ingreso al Perú sería positiva, ya que aportaría en la economía por el aumento de turismo. Alf Aasmann, director general para Brasil de Emirates, no descartó que en un futuro cercano pueda concretarse esta operación; sin embargo, primero es necesario evaluar el mercado peruano. En la actualidad, Emirates vuela diariamente desde Dubai a Sao Paulo y a partir de enero del 2012 cubrirá la ruta Dubai - Río de Janeiro Buenos Aires, también con una frecuencia al día. Las naves que utiliza son los B777 con capacidad para 354 pasajeros.

Por ello, dijo que para definir un nuevo destino es importante determinar si el mercado y sus vecinos responderán a esta oferta, un análisis que podría tardar unos tres años. "El mercado peruano es hoy pequeño, siendo realistas, pero con un fuerte potencial para el crecimiento", explicó, tras remarcar que un primer paso es contar con un representante en el país, como lo es la empresa Agunsa con la que han iniciado un trabajo ("Emirates Airline no descarta volar a lima en un futuro cercano", 2011).

A pesar que actualmente existen competencias como Sky Airlines, las cuales han ingresado con un concepto Low Cost, se dirigen a mercados opuestos con diferenciación 
entre ambos conceptos, por lo que no afectaría una con otra, cada uno de estos tienen diferente tipo de cliente y estrategias para su mercado.

Los clientes Emirates son aquellos que buscan más allá que llegar al destino, desean vivir una experiencia con valor agregado y están dispuestos a pagar por ello. Mientras por otro lado los clientes Low Cost, buscan llegar al destino sin importar la experiencia del vuelo, solo desean llegar.

Aerolíneas Emirates busca reproducir la experiencia de glamur durante sus vuelos. La industria a la que pertenece, se caracteriza por no tener comodidades de servicio. Para muchos pasajeros la experiencia que brindaba la aerolínea era sofisticada y de muy alta gama.

Asimismo, la aerolínea sigue expandiendo su red a destinos aún más lejanos. Los pronósticos demuestran que el crecimiento continuo sólido para las rutas entre Australia y las Américas, las cuales eran un mercado al que podía ingresar. Uno de los últimos éxitos potenciales fue sus vuelos directos de New York y Milán, práctica que se podría replicar en otros grandes mercados sujetos a aprobación normativa de cada uno de ellos. 


\section{CONCLUSIONES}

- Aerolíneas Emirates es una de las aerolíneas más grandes al nivel mundial que brinda servicio de vuelos a pasajeros que buscan vivir experiencias con valor agregado durante sus trayectorias. Logrando fidelizarlo con la marca, creando lealtad hacia ella.

- Aerolíneas Emirates no sólo brindaba servicio de transporte, sino que también aumento el alcance de sus comodidades de lujo y en sus flotas adapto diseños de lujo como suites de primera clase, "spas de ducha" y un bar de servicio completo.

- Emirates contaba con un equipo de trabajo de más de 55,000 empleados, quienes provenían de más de 148 países diferentes y hablaban más de 50 idiomas, lo que buscaba con esto era satisfacer de manera eficaz su diversa base de pasajeros.

- Emirates competía con aerolíneas europeas que brindaban transporte de tráfico de pasajeros y de carga. Marcas conocidas en el mercado como British Ariways, Air France, Lufthansa, Iberia, entre otros fueron las principales. Sin embargo, muchas de estas fueron afectadas por la nueva tendencia de las aerolíneas de precios bajos o conocidas como "Low cost", consolidándose con una estrategia de crecimiento, ya que esto impacto desde la experiencia del pasajero hasta la eficiencia del combustible a las marcas.

- Emirates tuvo como finalidad posicionarse en la mente del consumidor como una marca Premium de servicio con experiencia única viajera en el mercado, lo cual logró con mucho éxito en el mercado.

- La marca espera un crecimiento de $18 \%$ gracias a las nuevas innovaciones aeronáuticas en los siguientes años. Además, al tener como estrategia la planificación de rutas, se observó la oportunidad de ingresar a los países BRICS y en los mercados emergentes en general, dándole la ventaja de ser precursor en distintas ciudades. 
- Importante mencionar como Emirates Airlines busca tener mayor impacto al nivel global, a través de auspicio en los deportes, implementando una estrategia de publicidad en donde la consecuencia fue una aceptación positiva en el mercado.

- Con el supuesto de que la aerolínea ingrese al Perú, al ser una aerolínea conocida, tendría una aceptación optima por parte del mercado peruano. A su vez, aportaría de manera positiva en la economía y turismo del país. 


\section{RECOMENDACIONES}

En función a las conclusiones y análisis del desarrollo del caso Aerolíneas Emirates: Conectando lo desconectado. Se recomiendo realizar las siguientes actividades para el logro de los objetivos corporativos y mantener la estrategia de valor agregado en los clientes. A continuación, se detalla:

- Evaluar el mercado peruano y sus costumbres con mayor profundidad, ya que la ampliación del aeropuerto Jorge Chávez es una oportunidad muy abierta a que la Aerolínea pueda ingresar al mercado con su concepto desde el aeropuerto con mayor facilidad.

- Seguir con el auspicio en deportes mundiales, ya que con esto se está teniendo una estrategia mundial de marketing que aporta al recordatorio de la marca en diferentes países, así llegue o no llegue como destino final a ellos. Claro ejemplo: Perú

- Implementar diferentes e innovadores tipos de atención al cliente que no tengan acceso directo a la experiencia de viaje que brinda la aerolínea.

- Se recomienda continuar con la experiencia durante los vuelos, brindando un valor agregado a los clientes, y lo que hace que la marca sea una de las TOM en los mercados a los que se dirige.

- Dada la aparición de diferentes tipos de vuelos en aerolíneas low cost, se recomienda a la aerolínea mantener su concepto de negocio, que esta nueva estrategia no afecte ni dañe la imagen que tiene ya establecida en el mercado.

- Se recomienda seguir creciendo en los mercados emergentes que interconecten diferentes países y en diferentes continentes. 


\section{REFERENCIAS}

Alcacer, J. y Clayton, J. (2019). Aerolínea Emirates: Conectando lo desconectado (caso 9716-S12). Recuperado de sitio de internet de Universidad de Harvard: https://services.hbsp.harvard.edu/api/courses/624177/items/716S12-PDFSPA/sclinks/12a55a4554cb4c8a402d5f249ca0634f

Emirates. (2019). Destinos. $\quad$ Recuperado de https://www.emirates.com/ec/spanish/destinations/

Dominguez A. y Muñoz G. (2010). Métricas del Marketing. Madrid: ESIC Editorial

Lovelock, C. y Wirtz, J. (2015). Marketing de servicios: personal, tecnología y estrategia ( $7^{\text {a. }}$ ed.). México: Pearson

Emirates Airline no descarta volar a lima en un futuro cercano. (31 de mayo de 2011). TNEWS. Recuperado de http://www.tnews.com.pe/noticias/unot310511.htm

Ferrel, O. y Hartline, M. D. (2012). Estrategias de Marketing (5a ed.). México: Cengage Learning

Fred, D. Forest, D. (2017). Conceptos de administración estratégica (15ta ed.). México: Pearson Educación

Sky Airline espera cerrar el 2019 con el 7\% del mercado de vuelos low cost. (30 de marzo de 2019). Gestión. Recuperado de https://gestion.pe/economia/sky-airline-esperacerrar-2019-7-mercado-vuelos-low-cost-nndc-262875

Hoffman, K. (2007). Principios de Marketing y sus mejores prácticas. (3 ${ }^{\mathrm{a}}$. ed.). México: Thomson Editores

Homs, R. (2011). La Esencia de la Estrategia de Marketing. México: Cencage Learning

Caballar, J. A. (2012). Social Media $\left(1^{\circ}\right.$ Ed.) México: Alfaomega Grupo Editor

Kotler, P., Armstrong, G., y Amador Araújo, L. (2017). Fundamentos de marketing (13ª . ed.). México: Pearson Educación

Lamb, C., Hair, J. y McDaniel, C. (2011). Marketing (11ra ed.). México: Cencage Learning

Munuera, J. L. (2012). Estrategia de Marketing. España: ESIC Editorial.

Portal turismo. (2 de abril de 2019). Obras de ampliación del aeropuerto Jorge Chávez iniciarán en los próximos días. Recuperado de 
https://portaldeturismo.pe/noticia/obras-de-ampliacion-del-aeropuerto-jorgechavez-iniciaran-en-los-proximos-dias/

Porter M. (1982). Estrategia Competitiva. Técnicas para el análisis de los sectores industriales y de la competencia. ( $1^{\mathrm{a}}$ ed.). México: Continental.

Prieto Herrera. (2010). Merchandising. (2ª ed.). Bogotá: Ecoe Ediciones

Santesmases, M. (2012). Marketing: conceptos y estrategias. (6 ${ }^{\text {a }}$ ed). Madrid: Pirámide

Las 10 mejores aerolíneas para viajar en el 2019. (28 de Diciembre de 2018). Revista Cosas. Recuperado de https://cosas.pe/lifestyle/149951/ranking-mejores-aerolineas-2019/

Los peruanos gastan un promedio de USD $\$ 230$ por viaje. (25 de marzo de 2019). RPP. Recuperado de https://rpp.pe/economia/economia/los-peruanos-gastan-unpromedio-de-usd236-por-viaje-noticia-1187980

Nagle, T. T. (2002). Estrategia y Tácticas de Precios (3ra ed.). Madrid: Pearson Education

Zeithaml V., Bitner, M. y Gremler, D. (2009). Marketing de Servicios. (5ª ed.). México D.F.: McGraw-Hill. 